\title{
A Serious Game for Evaluating the Competencies of Environmental Consultants
}

\author{
Mariem Bouri $^{1}$, Lotfi Chraïbi ${ }^{1}$, Naoufal Sefiani ${ }^{2}$ \\ ${ }^{1}$ National school of applied sciences \\ Ziaten University Campus B.P 1818, Tangier, Morocco \\ mariem.bouri@etu.uae.ac.ma; lchraibi@uae.ac.ma \\ ${ }^{2}$ Faculty of Science and Technology \\ Ziaten University Campus B.P 416, Tangier, Morocco \\ nsefiani@uae.ac.ma
}

\begin{abstract}
Having a competent workforce is one of the key elements that enable organizations to improve their global performance Thus, it is important for an organization to manage the competencies of its staff in the best possible way. In this paper, we present a serious game named EnviRun', that evaluates the acquired competencies of environmental consultants _ The environmental consultant advises and assists industries on projects related to the environment and sustainable development_ Indeed, Competency evaluation allows the organizations to define the potential of existing competencies and to specify competencies that need to be improved. To this end, the first step was competency identification. Indeed, we developed a competency framework that includes competencies required by an environmental consultant. Thereafter, the game elements were designed. To evaluate the environmental consultants' competencies, an approach based on the interval-valued 2-tuple linguistic representation model has been proposed, this approach is more flexible when dealing with qualitative information.
\end{abstract}

Keywords: Competency, Interval-valued 2-tuple, Evaluation, Industries, Environment, Environmental consultants, Serious game.

\section{Introduction}

Improving overall performance is more and more a major element for organizations wishing to stand out in a market where co-competition is very tough. Indeed, having a competent staff is a major asset. Therefore, an effective competence management is extremely important [1]. A competency is "the ability to apply knowledge and skills to achieve intended results" [2] and competence management is "the way in which competencies in a corporation, of a group or individuals of the corporation are organized and controlled" [3]. Berio and Harzallah [4] stated that competence management includes four kinds of processes namely competence identification, competence assessment, competence acquisition and competence usage. In the present paper competence identification and assessment are mainly highlighted.

Competence management occupies an important place in the environmental field. In fact, the last version of the ISO 14001 standard [5] requires organizations to identify the competencies needed to achieve the environmental management system intended outcomes and to fill the gaps by taking actions to acquire necessary competencies [5], [6].

The present work fills within this framework and aims to present a new approach for the assessment of the environmental consultants' competencies _ The environmental consultant advises and assists industries on projects related to the environment and sustainable development_. Indeed, the assessment of competencies is usually a tough task. Therefore, we propose the use a serious game named EnviRun'. In the literature, we find out some works related competency assessment and development using serious games as Let's team! [7] conceived to develop and assess teamwork competency and Contreras et al. [8] proposed a model for the development of labor competencies based on serious games. EnviRun' helps to create a friendly environment by playing around a bord and to assess easily the knowwhom competencies. The game helps to evaluate competencies and thereafter to specify competencies that need to be developed.

It is difficult to evaluate competencies using crisp numbers, because competencies have an intangible character. Indeed, the assessment through linguistic variables is more adequate. Linguistic variable are variables whose values "are 
not numbers but words or sentences in a nature or artificial language" [9]. In this paper, we propose the use of intervalvalued 2-tuple linguistic variables proposed by Zhang [10]. This approach is more flexible to handle qualitative information.

The present paper is presented as follows, after a description of the basic concepts concerning the 2-tuple linguistic variables and interval-valued 2-tuple linguistic variables in section 2. The competency evaluation approach is introduced in section 3. Section 4 presents the game design and finally, some perspectives are pointed out in Section 5.

\section{Preliminaries}

\subsection{2-tuple linguistic variables}

Herrera and Martínez [11] introduced the 2-tuple fuzzy linguistic representation model that overcome the loss of information. Then, Chen and Tai [12] proposed a generalized fuzzy linguistic representation model. A 2-tuple linguistic variable is described as $\left(s_{i}, \alpha\right)$, where $s_{i}$ is a linguistic variable and $\alpha$ is a symbolic translation. In the following we will present some definitions:

Definition 1: Let $S=\left\{s_{0}, s_{1}, \ldots, s_{g}\right\}$ be a linguistic term set and $\beta \in[0,1]$ a value representing the result of a symbolic aggregation operation, then the generalized translation function $(\Delta)$ that translates $\beta$ into a 2-tuple linguistic variable is given by the following function [12]

$$
\begin{aligned}
& \Delta:[0,1] \rightarrow S \times\left[-\frac{1}{2 g}, \frac{1}{2 g}\right) \\
& \Delta(\beta)=\left(s_{i}, \alpha\right) \text { with } \begin{cases}s_{i}, & i=\operatorname{round}(\beta \bullet g) \\
\alpha=\beta-i / g, & \alpha \in\left[-\frac{1}{2 g}, \frac{1}{2 g}\right)\end{cases}
\end{aligned}
$$

Definition 2: The reverse function $\Delta^{-1}$ that returns the equivalent numerical value $\beta \in[0,1]$ of a 2-tuple is given as follows [12]:

$$
\begin{aligned}
& \Delta^{-1}: S \times[-0.5 / g, 0.5 / g) \rightarrow[0,1] \\
& \Delta^{-1}\left(s_{i}, \alpha\right)=\beta=i / g+\alpha
\end{aligned}
$$

\subsection{Interval-valued 2-tuple linguistic variables}

Zhang [10] proposed an interval-valued 2-tuple linguistic variable, as a generalization of the 2-tuple linguistic variable. Let us introduce some definitions:

Definition 3: Let $S=\left\{s_{i} \mid i=0,1,2, \ldots, g\right\}$ be a linguistic term set. An interval-valued 2-tuple is composed of two 2-tuples, denoted by $\left[\left(s_{i}, \alpha_{1}\right),\left(s_{j}, \alpha_{2}\right)\right]$, where $i \leq j, s_{i}\left(s_{j}\right)$ and $\alpha_{1}\left(\alpha_{2}\right)$ represent the linguistic label of the predefined linguistic term set $S$ and symbolic translation, respectively. An interval value $\left[\beta_{1}, \beta_{2}\right]\left(\beta_{1}, \beta_{2} \in[0,1], \beta_{1} \leq \beta_{2}\right)$ can be converted into an interval 2-tuple linguistic variable as follows [10]: 


$$
\Delta\left(\left[\beta_{1}, \beta_{2}\right]\right)=\left[\left(s_{i}, \alpha_{1}\right),\left(s_{j}, \alpha_{2}\right)\right] \text { with } \begin{cases}s_{i}, & i=\operatorname{round}\left(\beta_{1} \bullet g\right) \\ s_{j}, & j=\operatorname{round}\left(\beta_{2} \bullet g\right) \\ \alpha_{1}=\beta_{1}-i / g, & \alpha_{1} \in\left[-\frac{1}{2 g}, \frac{1}{2 g}\right) \\ \alpha_{2}=\beta_{2}-j / g, & \alpha_{2} \in\left[-\frac{1}{2 g}, \frac{1}{2 g}\right)\end{cases}
$$

The reverse function, that converts an interval 2-tuple linguistic variable can be converted into an interval value into an interval value $\left[\beta_{1}, \beta_{2}\right]\left(\beta_{1}, \beta_{2} \in[0,1], \beta_{1} \leq \beta_{2}\right)$ is given as follows [10]:

$$
\Delta^{-1}\left(\left[\left(s_{i}, \alpha_{1}\right),\left(s_{j}, \alpha_{2}\right)\right]\right)=\left[\beta_{1}, \beta_{2}\right]=\left[i / g+\alpha_{1}, j / g+\alpha_{2}\right]
$$

Definition 4: Let $\tilde{a}=\left[(s, \alpha),\left(s^{\prime}, \alpha^{\prime}\right)\right], \tilde{a}_{1}=\left[\left(s_{1}, \alpha_{1}\right),\left(s_{1}^{\prime}, \alpha_{1}^{\prime}\right)\right]$ and $\tilde{a}_{2}=\left[\left(s_{2}, \alpha_{2}\right),\left(s_{2}^{\prime}, \alpha_{2}^{\prime}\right)\right]$ be any three interval 2-tuples and let $\lambda \in[0,1]$, then their operations are defined as follows [13]

$$
\text { (1) } \begin{aligned}
& \tilde{a}_{1} \oplus \tilde{a}_{2}= {\left[\left(s_{1}, \alpha_{1}\right),\left(s_{1}^{\prime}, \alpha_{1}^{\prime}\right)\right] \oplus\left[\left(s_{2}, \alpha_{2}\right),\left(s_{2}^{\prime}, \alpha_{2}^{\prime}\right)\right] } \\
&=\Delta\left[\Delta^{-1}\left(s_{1}, \alpha_{1}\right)+\Delta^{-1}\left(s_{2}, \alpha_{2}\right), \Delta^{-1}\left(s_{1}^{\prime}, \alpha_{1}^{\prime}\right)+\Delta^{-1}\left(s_{2}^{\prime}, \alpha_{2}^{\prime}\right)\right] \\
& \text { (2) } \lambda \tilde{a}=\lambda\left[(s, \alpha),\left(s^{\prime}, \alpha^{\prime}\right)\right] \\
&=\Delta\left[\lambda \Delta^{-1}(s, \alpha), \lambda \Delta^{-1}\left(s^{\prime}, \alpha^{\prime}\right)\right]
\end{aligned}
$$

Definition 5: Let $\tilde{a}_{1}=\left[\left(s_{1}, \alpha_{1}\right),\left(s_{1}^{\prime}, \alpha_{1}^{\prime}\right)\right]$ and $\tilde{a}_{2}=\left[\left(s_{2}, \alpha_{2}\right),\left(s_{2}^{\prime}, \alpha_{2}^{\prime}\right)\right]$ be any two interval-valued 2-tuple linguistic variables. The distance $\left(d_{\text {ITD }}\right)$ between $\tilde{a}_{1}$ and $\tilde{a}_{2}$ is defined as [13]

$$
d_{I T D}\left(\tilde{a}_{1}, \tilde{a}_{2}\right)=\Delta\left[\frac{1}{2}\left(\left|\Delta^{-1}\left(s_{1}, \alpha_{1}\right)-\Delta^{-1}\left(s_{2}, \alpha_{2}\right)\right|+\left|\Delta^{-1}\left(s_{1}^{\prime}, \alpha_{1}^{\prime}\right)-\Delta^{-1}\left(s_{2}^{\prime}, \alpha_{2}^{\prime}\right)\right|\right)\right]
$$

Definition 6: Let $\tilde{a}_{i}=\left\{\left[\left(s_{i}, \alpha_{i}\right),\left(s_{i}^{\prime}, \alpha_{i}^{\prime}\right)\right]\right\}(i=1,2, \ldots, n)$ be a set of interval-valued 2-tuples, $w=\left(w_{1}, w_{2}, \ldots, w_{n}\right)^{T}$ is the weight vector of regarding interval 2-tuple, with $w_{i} \in[0,1]$ and $\sum_{i=1}^{n} w_{i}=1$. The Interval-Valued 2-tuple Weighted Average (IVTWA) is given as follows [10]

$$
\operatorname{IVTWA}\left(\tilde{a}_{1}, \tilde{a}_{2}, \ldots, \tilde{a}_{n}\right)=\Delta\left[\sum_{i=1}^{n} w_{i} \Delta^{-1}\left(s_{i}, \alpha_{i}\right), \sum_{i=1}^{n} w_{i} \Delta^{-1}\left(s_{i}^{\prime}, \alpha_{i}^{\prime}\right)\right]
$$




\section{Competency evaluation approach}

To evaluate competencies, the organization is asked to select specific competencies to be evaluated $P_{j}(j=1,2, \ldots, n)$ and the environmental consultants to be assessed $A_{i}(i=1,2, \ldots, m)$. Moreover, appraisers $E_{k}(k=1,2, \ldots, K)$ are selected. A weight $\lambda_{k}$ will be assigned to each appraiser $E_{k}(k=1,2, \ldots, K)$ in order to express his/her importance in the assessment process where, $\lambda_{k}>0$ and $\sum_{k=1}^{K} \lambda_{k}=1(k=1,2, \ldots, K)$. Furthermore, let $S=\left\{s_{0}=\right.$ None $(\mathrm{N}), s_{1}=$ Very Low (VL), $s_{2}=$ Low (L), $s_{3}=\operatorname{Medium}(\mathrm{M}), s_{4}=\operatorname{High}(\mathrm{H}), s_{5}=\operatorname{Very} \operatorname{High}(\mathrm{VH}), s_{6}=$ Extremely High $\}$ be the linguistic term set.

To assess the competency level. Each appraiser $E_{k}$ will select linguistic terms from the linguistic term set $S$. Thereafter, the assessments will be converted into interval-valued 2-tuple linguistic variables as follows:

- A grade such as Very Low (VL) can be written as $\left[\left(s_{1}, 0\right),\left(s_{1}, 0\right)\right]$

- An interval grade such as Very Low-Low (VL-L), means that the given assessment is between Very Low and Low , $\left[\left(s_{1}, 0\right),\left(s_{2}, 0\right)\right]$

Therefore, let $\tilde{C}_{k}=\left(\tilde{c}_{i j}^{k}\right)_{m \times n}=\left(\left[\left(s a_{i j}^{k}, 0\right),\left(t a_{i j}^{k}, 0\right)\right]\right)_{m \times n}$ be an interval 2-tuple linguistic assessment matrix corresponding to the acquired competency level where, $\tilde{c}_{i j}^{k}$ represents the interval 2-tuple value related to the linguistic information provided by $E_{k}$ on the assessment of the competency $P_{j}$ acquired by the environmental consultant $A_{i} ; s a_{i j}^{k}, t a_{i j}^{k} \in S$ and $s a_{i j}^{k} \leq t a_{i j}^{k} i=1,2, \ldots, \mathrm{m} \quad j=1,2, \ldots, \mathrm{n} \quad k=1,2, \ldots, K$.

The assessments of all appraisers regarding the acquired competencies level are then aggregated to construct a collective interval 2-tuple linguistic assessment matrix $\tilde{C}=\left(\tilde{c}_{i j}\right)_{m \times n}$, where,

$$
\begin{aligned}
& \tilde{c}_{i j}=\left(\left[\left(s a_{i j}, \alpha a_{i j}\right),\left(t a_{i j}, \varepsilon a_{i j}\right)\right]\right)_{m \times n}=\operatorname{IVTWA}\left(\tilde{c}_{i j}^{1}, \tilde{c}_{i j}^{2}, \ldots, \tilde{c}_{i j}^{K}\right) \\
& =\Delta\left[\sum_{k=1}^{K} \lambda_{k} \Delta^{-1}\left(s a_{i j}^{k}, 0\right), \sum_{k=1}^{K} \lambda_{k} \Delta^{-1}\left(t a_{i j}^{k}, 0\right)\right] \quad i=1,2, \ldots, m, \quad j=1,2, \ldots, n
\end{aligned}
$$

If the organization wishes to define the competencies to be improved, two more steps are required. The first step is to evaluate the required competencies level of the environmental consultant position. Indeed, let $\tilde{R}_{k}=\left(\tilde{r}_{j}^{k}\right)_{1 \times n}=\left(\left[\left(s r_{j}^{k}, 0\right),\left(t r_{j}^{k}, 0\right)\right]\right)_{1 \times n}$ be an interval 2-tuple linguistic assessment matrix corresponding to the required level where, $\tilde{r}_{j}^{k}$ represents the interval 2-tuple value related to the linguistic information provided by $E_{k}$ on the assessment of the competency $P_{j}$ required by the environmental consultant position; $s r_{j}^{k}, t r_{j}^{k} \in S$ and $s r_{j}^{k} \leq t r_{j}^{k} j=1,2, \ldots, n k=1,2, \ldots, K$. The assessments of all appraisers regarding the required competencies level are then aggregated to construct a collective interval 2-tuple linguistic assessment matrix $\tilde{R}=\left(\tilde{r}_{j}\right)_{1 \times n}$, where,

$$
\begin{array}{rlrl}
\tilde{r}_{j} & =\left[\left(s r_{j}, \alpha r_{j}\right),\left(t r_{j}, \varepsilon r_{j}\right)\right]=\operatorname{IVTWA}\left(\tilde{r}_{j}^{1}, \tilde{r}_{j}^{2}, \ldots, \tilde{r}_{j}^{K}\right) \\
& =\Delta\left[\sum_{k=1}^{K} \lambda_{k} \Delta^{-1}\left(s r_{j}^{k}, 0\right), \sum_{k=1}^{K} \lambda_{k} \Delta^{-1}\left(t r_{j}^{k}, 0\right)\right] & j=1,2, \ldots, n
\end{array}
$$


The second step is to compute the gap between the acquired and required competencies level. For that purpose, the distance defined by equation (7) is used. The gap can be written as:

$$
\begin{aligned}
& d_{I T D}\left(\tilde{c}_{i j}, \tilde{r}_{j}\right)=\Delta\left[\frac{1}{2}\left(\left|\Delta^{-1}\left(s a_{i j}, \alpha a_{i j}\right)-\Delta^{-1}\left(s r_{j}, \alpha r_{j}\right)\right|+\left|\Delta^{-1}\left(t a_{i j}, \varepsilon a_{i j}\right)-\Delta^{-1}\left(t r_{j}, \varepsilon r_{j}\right)\right|\right)\right] \\
& i=1,2, \ldots, m, \quad j=1,2, \ldots, n
\end{aligned}
$$

The greater the distance, the greater the gap between the acquired and required level, and consequently the organization should address these gaps by implementing appropriate actions as training to acquire the necessary competencies.

\section{Game design}

Evaluating the acquired skills of an environmental consultant proves to be an arduous task. Therefore, we propose a serious game named EnviRun' that provides an enabling environment where direct competency assessment is bypassed and where appraisers can also participate to the game.

EnviRun's main objective is to allow the organizations to evaluate the competencies acquired by the environmental consultants and to know consequently the competencies that need to be improved. To design the game, competency identification proved to be an ineluctable step. Indeed, we first listed out competencies that are required by an environmental consultant _The environmental consultant advises and assists industries on projects related to the environment and sustainable development_ Three main categories have been considered in the competency identification process: Knowledge, know-how and know-whom. According to Harzallah and Vernadat [14] The knowledge "covers everything learned at school or everything that requires a preliminary training"; the know-how is acquired through action and it includes procedural know-how and empirical know-how (tricks, rule of thumbs ...) and finally the know-whom which allows to use a specific behaviour for a given situation. Table 1 give some examples of competencies required by the environmental consultant position.

Table 1: Examples of competencies required by the environmental consultant position.

\begin{tabular}{|l|l|}
\hline Category of competencies & Competencies (examples) \\
\hline \multirow{5}{*}{ Knowledge } & To know the requirements of the ISO 14001:2015 standard \\
\cline { 2 - 2 } & To know the environmental laws and regulations \\
\cline { 2 - 2 } & $\begin{array}{l}\text { General knowledge in environment and sustainable } \\
\text { development }\end{array}$ \\
\hline \multirow{5}{*}{ Know-how } & Develop awareness tools \\
\cline { 2 - 2 } & To propose technical solutions \\
\cline { 2 - 2 } & Carry out environmental impact studies \\
\hline & Stress management \\
\hline & Teamwork \\
\cline { 2 - 2 } & To show sense of continuous improvement \\
\cline { 2 - 2 } & Relational ease \\
\hline
\end{tabular}

Once the competencies identified, the next step was to select the game typology, a digital (e.g. video games...) or a non-digital game (e.g. board games, card games ...). Given our objective, we opt for a non-digital game, because it allows the appraisers to create a friendly environment. Furthermore, it enables to evaluate easily the environmental consultants' know-whom by observing their behaviours during the game. Fig. 1. Shows the EnviRun's board. 


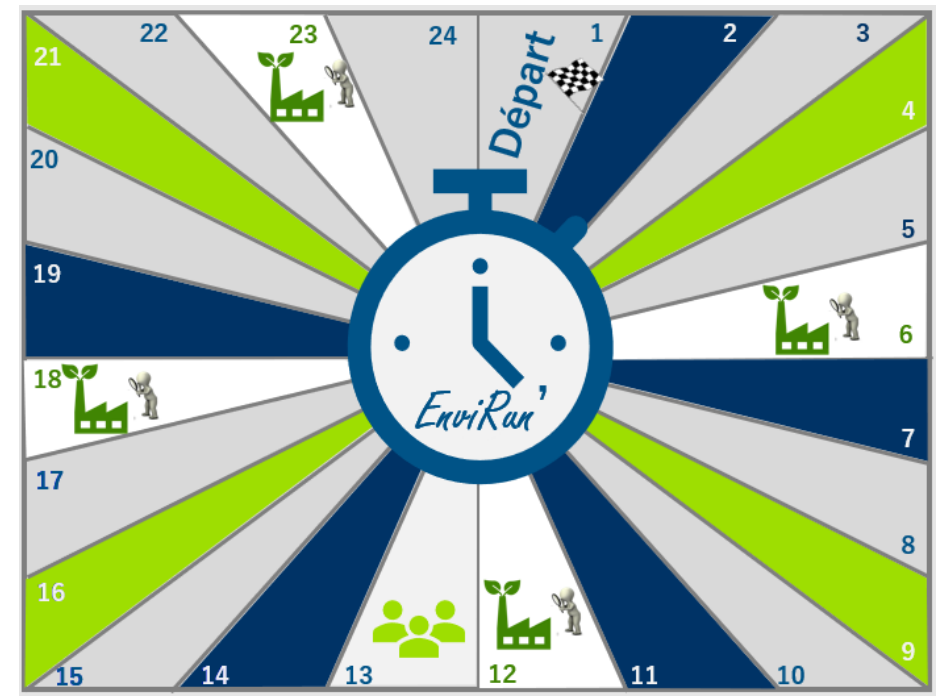

Fig. 1: EnviRun's board.

EnviRun' includes three main topics: wastes management (Dark blue boxes), ISO 14001:2015 standard [2] (Grey boxes) and general knowledge in environment and sustainable development (Green boxes). For each topic, several questions were designed. For instance, in the general knowledge topic, we find out questions about sustainable development, water consumption, environmental regulations, gaseous effluents ... The white boxes (Number 6, 12, 18 and 23) include real-life situations, which enable the appraisers to assess not only the knowledge of the environmental consultants but also their know-how and know-whom. Each situation must be solved in a predetermined time. Finally, the box number 13, aims to promote the group work and thus, to assess different know-whom competencies like teamwork, relational ease, communication skills ... EnviRun' was designed flexibly. Indeed, the organization wishing to evaluate its collaborators' competencies, can select specific competencies to be assessed and keep only the questions and situations that are related to these competencies. Each question and each situation have an equivalent number of points and once a specific number of points is reached the game is over. Towards the end of the game, the evaluators have a clear idea of each player's competency level, which allows him/her to evaluate the acquired competencies.

\section{Conclusion}

In this paper, we present a serious game named EnviRun' that aims to evaluate the environmental consultants' competencies. EnviRun' is a conceived flexibly and helps to create a friendly environment. The competency assessment is carried out by using the interval-valued 2-tuple linguistic approach. Indeed, this approach is more flexible when dealing with qualitative information. The competency assessment enables both the assessment of the acquired competency level and to identify of the gaps between acquired and required competency level, which allows the organizations to implement the necessary actions to address these gaps.

As perspectives, we will experiment the EnviRun' serious game in a company that is wishing to evaluate its environmental consultants.

\section{References}

[1] M. Bouri, L. Chraïbi, and N. Sefiani, "On the assessment of the individual competence level for an environmental manager: Case of logistics sector," 2018 International Colloquium on Logistics and Supply Chain Management (LOGISTIQUA). IEEE, 2018, pp. 122-127, doi: 10.1109/LOGISTIQUA.2018.8428299.

[2] ISO, ISO 9000 Systèmes de management de la qualité - Principes essentiels et vocabulaire. Editions afnor, 2015. 
[3] M. Harzallah, G. Berio, and F. Vernadat, "Analysis and modeling of individual competencies: toward better management of human resources," IEEE Trans. Syst. Man Cybern.-Part Syst. Hum., vol. 36, no. 1, pp. 187-207, 2006.

[4] G. Berio and M. Harzallah, "Knowledge Management for Competence Management," J. Univers. Knowl. Manag., vol. 0 , no. $1,2005$.

[5] ISO, NF EN ISO 14001: systèmes de management environnemental - exigences et lignes directrices pour son utilisation. Éditions Afnor, 2015.

[6] ISO, NF EN ISO 14004 : Systèmes de management environnemental -- Lignes directrices générales pour la mise en application, Éditions Afnor. 2016.

[7] M. Guenaga, A. Eguíluz, A. Rayón, A. Núñez, and E. Quevedo, "A serious game to develop and assess teamwork competency," 2014 International Symposium on Computers in Education (SIIE). IEEE, 2014, pp. 183-188.

[8] M. Contreras, D. Bonilla, and A. Peña Pérez Negrón., "Proposal of a Model for the Development of Labor Competencies Based on Serious Games in the Context of Industry 4.0," "International Conference on Software Process Improvement. Springer, Cham, 2018, pp. 80-87.

[9] L. A. Zadeh, "The concept of a linguistic variable and its application to approximate reasoning-II," Inf. Sci., vol. 8, no. 4, pp. 301-357, Jan. 1975, doi: 10.1016/0020-0255(75)90046-8.

[10]H. Zhang, "The multiattribute group decision making method based on aggregation operators with interval-valued 2tuple linguistic information," Math. Comput. Model., vol. 56, no. 1-2, pp. 27-35, 2012, doi: https://doi.org/10.1016/j.mcm.2012.01.001.

[11]F. Herrera and L. Martinez, "A 2-tuple fuzzy linguistic representation model for computing with words," IEEE Trans. Fuzzy Syst., vol. 8, no. 6, pp. 746-752, Dec. 2000, doi: 10.1109/91.890332.

[12]C. T. Chen and W.S. Tai, "Measuring the Intellectual Capital Performance based on 2-tuple Fuzzy Linguistic Information," 10th Annu. Meet. APDSI Asia Pac. Reg. Decis. Sci. Inst., 2005, vol. 20.

[13]M.-M. Shan, P. Li, and H.-C. Liu, "Interval 2-Tuple Linguistic Distance Operators and Their Applications to Supplier Evaluation and Selection," Mathematical Problems in Engineering, 2016.

[14] M. Harzallah and F. Vernadat, "IT-based competency modeling and management: from theory to practice in enterprise engineering and operations," Comput. Ind., vol. 48, no. 2, pp. 157-179, Jun. 2002, doi: 10.1016/S01663615(02)00003-9. 